Research Paper

\title{
Platelet Rich Fibrin (P.R.F.) in Reconstructive Surgery of Atrophied Maxillary Bones: Clinical and Histological Evaluations
}

\author{
Marco Tatullo ${ }^{1,2,3}{ }^{*}$, Massimo Marrelli 2,3* , Michele Cassetta ${ }^{4}$, Andrea Pacifici ${ }^{4}$, Luigi Vito Stefanelli ${ }^{4}$, \\ Salvatore Scacco ${ }^{1}$, Gianna Dipalma ${ }^{2}$, Luciano Pacifici ${ }^{4}$, Francesco Inchingolo 2,5 *
}

1. Dept. of Basic Medical Science, University of Bari, Italy;

2. Unit of Maxillofacial Surgery, Calabrodental clinic, Crotone, Italy;

3. Tecnologica, Research Institute in Regenerative Medicine, Crotone, Italy;

4. Department of Oral and Maxillofacial sciences, University of Rome "Sapienza", Italy;

5. Department of Dental Sciences and Surgery, University of Bari, Italy.

* These Authors contributed equally to this work.

$\triangle$ Corresponding author: Dr. Marco Tatullo DDS, PhDs. Tecnologica Research Institute, Crotone, Italy. St. E. Fermi, Crotone, Italy. Dept. of Basic Medical Sciences - University of Bari - Bari, Italy. P.ce G. Cesare, 70100 Bari, Italy.

() Ivyspring International Publisher. This is an open-access article distributed under the terms of the Creative Commons License (http://creativecommons.org/ licenses/by-nc-nd/3.0/). Reproduction is permitted for personal, noncommercial use, provided that the article is in whole, unmodified, and properly cited.

Received: 2012.08.28; Accepted: 2012.10.17; Published: 2012.11.07

\begin{abstract}
Introduction. Maxillary bone losses often require additional regenerative procedures: as a supplement to the procedures of tissue regeneration, a platelet concentrate called PRF (Platelet Rich Fibrin) was tested for the first time in France by Dr. Choukroun.

Aim of the present study is to investigate, clinically and histologically, the potential use of PRF, associated with deproteinized bovine bone (Bio-Oss), as grafting materials in pre-implantology sinus grafting of severe maxillary atrophy, in comparison with a control group, in which only deproteinized bovine bone (Bio-Oss) was used as reconstructive material.

Materials and Methods. 60 patients were recruited using the cluster-sampling method; inclusion criteria were maxillary atrophy with residual ridge $<5 \mathrm{~mm}$. The major atrophies in selected patients involved sinus-lift, with a second-look reopening for the implant insertion phase. The used grafting materials were: a) Bio-Oss and b) amorphous and membranous PRF together with Bio-Oss. We performed all operations by means of piezosurgery in order to reduce trauma and to optimize the design of the operculum on the cortical bone. The reopening of the surgical area was scheduled at 3 different times.

Results. 72 sinus lifts were performed with subsequent implants insertions.

We want to underline how the histological results proved that the samples collected after 106 days (Early protocol) with the adding of PRF were constituted by lamellar bone tissue with an interposed stroma that appeared relaxed and richly vascularized.

Conclusions. The use of PRF and piezosurgery reduced the healing time, compared to the I50 days described in literature, favoring optimal bone regeneration. At 106 days, it is already possible to achieve good primary stability of endosseous implants, though lacking of functional loading.
\end{abstract}

Key words: Reconstructive Surgery; Platelet Rich Fibrin; Grafting Materials; Bone replacement. 


\section{Introduction}

Maxillary atrophy is an increasingly common clinical condition and its management requires patient-specific procedures, allowing for a reduced intra-operative timing and maximum postoperative compliance.

The causes that lead to focal or generalized atrophy lie in multiple factors, but edentulism plays a primary role ${ }^{1}$.

After loss of compromised teeth, resorption is maximum in the first year and more marked in the anterior areas than in the posterior ones ${ }^{2}$.

In the following years, there is a minimum but constant decrease in the residual bone quantity.

Bone density influences the operative protocol and the choice of the type of implant used in order to replace the lost teeth. Maxillary bone losses often require additional surgical procedures ${ }^{3-6}$.

A grafting material takes the role of substitute of the insufficient bone tissue if it meets biocompatibility criteria, if it has an optimal response to biomechanical stress and a great capacity to replace the functions of synthesis/reshaping of the bone structure, essential for a correct turnover and for a good functionality of the tissue ${ }^{7}$.

Of course gold standard is a biomaterial with the greatest biocompatibility: the autologous bone collected from the intraoral area, thanks to the same embryogenetic derivation and for the presence of the Bone Morphogenetic Protein (BMP) favoring osteoinduction, is the perfect material for sinus lift. Besides, it is the only material having osteogenic properties in addition to osteoinductive and osteoconductive properties ${ }^{8-13}$.

From the second half of the 1990s, the attention of the "Oral and Maxillofacial Surgery Community" was attracted by a series of scientific papers: they claimed that a platelet-derived growth factor could be valid not only for hemostasis, but also in the emerging field of bone grafting 14-22.

In the last years, a platelet concentrate called PRF (Platelet Rich Fibrin) was tested for the first time in France by Choukroun et al.

PRF belongs to a new generation of platelet concentrates: PRF is obtained without adding anticoagulants like heparin, EDTA, bovine thrombin etc. During the production of PRF, other cellular elements like leukocytes are activated, in addition to platelets. After the artificial hemostatic and inflammatory phenomenon induced by centrifugation, they release cytokines $^{16-18}$. Then we will find three pro-inflammatory cytokines (IL-1 $\beta$, IL-6 e TNFa), an anti-inflammatory cytokine (IL-4) and a key promoter of angiogenesis (VEGF) 14,15,23,24.

PRF is then able to regulate inflammation and to stimulate the immune process of chemotaxis ${ }^{14,15,23}$. PRF is an autologous grafting material that eliminates any risk of disease transmission; besides, its jelly-like consistency favors stability of the clot and of the grafting material. This natural material seems to accelerate the physiological wound healing; besides, in association with bone grafts, it seems to accelerate new bone formation $14,15,19,20$.

PRF has many advantages:

- Simple and cheap protocol

- Contains a great quantity of fibrins, platelets and leukocytes 18

- Accelerates angiogenesis 14,15 , multiplication of fibroblasts and osteoblasts, and cicatrization.

Aim of the work: the aim of the present study is to investigate, clinically and histologically, about the potential of PRF, used as grafting material in pre-implant reconstructive surgery of severe maxillary atrophy; in particular, we want to assess what changes histologically and clinically after sinus lift procedures at 106-120-180 days, to determine if the use of PRF is able to accelerate the process of bone regeneration, which is essential to promote implant stability. This study also includes a control group, in which only deproteinized bovine bone (Bio-Oss) was used as reconstructive material, used without PRF.

\section{Materials and Methods}

Patients were recruited using the cluster-sampling technique, in order to obtain a heterogeneous sample, representing the macro-area of South Italy.

This study focused on 60 patients (48 females and 12 males aged between 43 and 62 years), adequately informed of the surgical and rehabilitative procedures they had to undergo. In order to minimize the operator's bias, surgical procedures were performed by only two operators, maintaining the same equipe in all surgical procedures performed.

Exclusion criteria were:

- Diabetes

- Hemocoagulative disorders

- Incompetence/Immunological deficiency

- Previous radiant therapies of the head-neck area

- Anomalies of normal bone physiology

- Therapies with Bisphosphonates

- Smokers or ex-smokers. Inclusion criteria were:

- Maxillary atrophy, with residual ridge $<5 \mathrm{~mm}$, found with a preoperative radiological and tomographic evaluation 
- Need of anatomo-functional rehabilitation of the posterior maxilla owing to toothlessness.

The major atrophies in selected patients involved the sinus-lift procedure, with a second-look reopening for the implant insertion phase.

Before any treatments, the patients were properly informed about the advantages and disadvantages of all the planned procedures, first verbally and then with a written form for the informed consent. The present study always obeyed the rules established in the 1975 Declaration of Helsinki, then revised in 1983.

\section{Preparation for surgery}

Bone loss was assessed by first-level radiological investigations with a standardized procedure and Computed Tomography of the area to reconstruct: the choice of implants was case-specific, subsequent to bone increment and according to the type of reconstruction required.

Before any treatment, a complete periodontal treatment was planned.

Before surgery, Amoxicillin were administered ( $2 \mathrm{~g}$ per os, $1 \mathrm{~h}$ before surgery and $1 \mathrm{~g}$ per os, $1 / 2$ hour after surgery).

\section{Preparation of PRF}

The protocol is performed according with Choukroun's procedure, introduced with the European Directive no. 2004/23/CE of March 31, 2004.

The patient's venous blood sample was taken before surgery.

The blood is placed in a $10 \mathrm{ml}$ glass test tubes, without anticoagulant, and immediately centrifuged at $3000 \mathrm{rpm}$ for 10 minutes. The biological steps of this centrifugation involve that the circulating blood thrombin turns fibrinogen into fibrin: this fibrin then places at the centre of the test tube.

The PRF obtained will be used in two ways:

- a part of it is used as a filling material, with a gelatinous consistency and an amorphous shape;

- the remaining part is shaped in order to form a resistant fibrin membrane which can be transferred onto Schneider's membrane.

\section{First Surgical Stage}

Maxillary sinus lift was performed according to Tatum's technique, involving an incision on the crestal ridge of the maxilla in order to access to the maxillary sinus.

The osteotomy to delimit the bone window was performed by piezosurgery. The use of piezosurgery involves considerable advantages for the oral surgeon: an osteotomy with micrometric cut for complete surgical accuracy and a high intraoperative sensibility; a site-specific selective cut to minimize the damage to the soft tissues, which is an important quality to preserve the sinus membrane while creating the trans-cortical access window in sinus lift; an excellent intraoperative visibility thanks to a bloodless surgical field, ensured by the effect of cavitation.

At this point, the protocol involved the sinus lift to be performed with two different grafting materials: the use of the two grafting materials was selected by a randomized procedure with dichotomous outcomes, thanks to the use of a different patient code and of a random number generator managed by an operator not involved in the study group and unaware of the ongoing trial.

The grafting materials were:

1. Use of Deproteinized bovine bone (Bio-Oss): a small quantity of Bio-Oss was pushed into the sub-sinus access cavity, subject to Valsalva's maneuver with negative outcome.

2. Use of amorphous and membranous PRF togheter with Bio-Oss: a small quantity of amorphous PRF was pushed into the sub-sinus access cavity, subject to Valsalva's maneuver with negative outcome. A first mass of amorphous PRF was placed on the base of the maxillary sinus, together with a second mass of amorphous PRF under the first amorphous mass. With the bone widow being partially occluded by the added PRF, we predisposed the insertion of Bio-Oss mixed with a small quantity of gelatinous PRF, in order to have a mixture that could be compacted in the crest area, under the small masses of amorphous PRF that were previously placed. This led to a clear mechanical effect of compression, favoring the compacting of the grafting material in the crest area and, at the same time, reaching the goal of sinus lift.

At the end of this stage, two membranes were placed. They were obtained from the flattening of the remaining PRF between two sterile gauzes and then placed in order to close the access area to the sinus site. Lastly, the bone window was closed to avoid traumatisms, the flap was replaced and then the mucosal areas were sutured through a non-resorbable material.

\section{Second Surgical Stage}

The surgical phase of sinus lift, performed in two stages, as the protocol requires, did not allow proceeding with implant surgery due to the small quantity of maxillary bone $(<5 \mathrm{~mm})$. The reopening of the surgical area was scheduled at different times.

The 60 patients were given an anonymous code by an operator not included into the research group. 
With the use of a code generator, the patients were given the following codes:

a) $\mathrm{N}^{\circ} 20$ codes, corresponding to the 20 patients assigned to the protocol named "early"

b) $\mathrm{N}^{\circ} 20$ codes, corresponding to the 20 patients of "intermediate" protocol

c) $\mathrm{N}^{\circ} 20$ codes, corresponding to the 20 patients of "late" protocol

"Early" protocol involved a surgical second-look for implant surgery 106 days after sinus lift.

"Intermediate" protocol involved a surgical second-look for implant surgery 120 days after sinus lift.

"Late" protocol involved a surgical second-look for implant surgery 150 days after sinus lift.

Each protocol included 4 patients ( 1 male and 3 females) presenting with bilateral atrophy (residual ridge $<5 \mathrm{~mm}$ ) of the maxillary cortex. By convention, we define as "Test-Side" the maxillary side in which sinus lift was performed with PRF addiction, and as "Control-Side" the maxillary side in which sinus lift was performed without PRF addiction. The 12 pa- tients who received bilateral lift allowed to evaluate the result of both PRF technique and Bio-Oss only technique. Therefore, in these patients, there will be both the "Test-Side" and the "Control-Side".

The 20 patients of each protocol received the following treatment in the "First Surgical Stage":

- 6 patients received a sinus lift with the only use of Bio-Oss;

- 10 patients received a sinus lift with the use of both PRF and Bio-Oss;

- 4 patients presented with a major bilateral atrophy, therefore received two sinus lifts with the use of PRF and Bio-Oss (Test-Side) and of Bio-Oss only (Control-Side).

Before implant insertion, transcortical bone was sampled from the area where sinus lift was performed. (Table 1)

The sampled material was sent to a lab of Anatomical Pathology.

Table I. Synoptic evaluation of patients.

\begin{tabular}{|c|c|c|c|c|c|c|c|c|}
\hline & Patient & Age & Gender & Test-Side & Implants & Protocol & Failures & Complications \\
\hline 1 & M.F. & 61 & $\mathrm{M}$ & Right & 6 & L Bilat. & $\mathrm{NO}$ & $\mathrm{NO}$ \\
\hline 2 & S.A. & 58 & $\mathrm{~F}$ & $\mathrm{R}$ & 3 & E & NO & $\mathrm{NO}$ \\
\hline 3 & M.G. & 58 & F & $\mathrm{R}$ & 3 & E & NO & $\mathrm{NO}$ \\
\hline 4 & R.C. & 46 & F & $\mathrm{R}$ & 2 & I & NO & $\mathrm{NO}$ \\
\hline 5 & F.P. & 44 & $\mathrm{~F}$ & $\mathrm{R}$ & 3 & $\mathrm{~L}$ & NO & NO \\
\hline 6 & F.I. & 55 & $\mathrm{~F}$ & $\mathrm{R}$ & 3 & I & $\mathrm{NO}$ & $\mathrm{NO}$ \\
\hline 7 & F.P. & 60 & M & Left & 2 & $\mathrm{~L}$ & $\mathrm{NO}$ & $\mathrm{NO}$ \\
\hline 8 & G.M.A. & 62 & $\mathrm{~F}$ & $\mathrm{R}$ & 4 & I Bilat. & NO & $\mathrm{NO}$ \\
\hline 9 & A.V. & 47 & F & $\mathrm{R}$ & 3 & E & NO & $\mathrm{NO}$ \\
\hline 10 & E.G. & 50 & F & $\mathrm{R}$ & 3 & I & $\mathrm{NO}$ & $\mathrm{NO}$ \\
\hline 11 & A.D. & 52 & F & $\mathrm{R}$ & 2 & $\mathrm{~L}$ & NO & $\mathrm{NO}$ \\
\hline 12 & G.F. & 54 & F & $\mathrm{R}$ & 3 & $\mathrm{~L}$ & $\mathrm{NO}$ & $\mathrm{NO}$ \\
\hline 13 & V.S. & 45 & F & $\mathrm{L}$ & 2 & $\mathrm{E}$ & $\mathrm{NO}$ & $\mathrm{NO}$ \\
\hline 14 & V.D. & 48 & $\mathrm{~F}$ & $\mathrm{~L}$ & 3 & I & NO & $\mathrm{NO}$ \\
\hline 15 & R.C. & 61 & M & $\mathrm{L}$ & 4 & E Bilat. & NO & $\mathrm{NO}$ \\
\hline 16 & A.G. & 51 & $\mathrm{~F}$ & $\mathrm{R}$ & 3 & $\mathrm{~L}$ & NO & $\mathrm{NO}$ \\
\hline 17 & L.T. & 55 & F & $\mathrm{L}$ & 5 & E Bilat. & $\mathrm{NO}$ & NO \\
\hline 18 & V.L. & 53 & F & $\mathrm{L}$ & 3 & $\mathrm{~L}$ & NO & $\mathrm{NO}$ \\
\hline 19 & S.D. & 49 & F & $\mathrm{L}$ & 3 & I & $\mathrm{NO}$ & $\mathrm{NO}$ \\
\hline 20 & G.T. & 60 & F & $\mathrm{R}$ & 2 & $\mathrm{E}$ & NO & $\mathrm{NO}$ \\
\hline 21 & Y.F. & 43 & F & $\mathrm{R}$ & 3 & I & $\mathrm{NO}$ & $\mathrm{NO}$ \\
\hline 22 & D.B. & 62 & F & $\mathrm{R}$ & 5 & L Bilat. & NO & NO \\
\hline 23 & F.D. & 43 & F & $\mathrm{L}$ & 3 & $\mathrm{~L}$ & NO & $\mathrm{NO}$ \\
\hline 24 & G.Z. & 58 & F & $\mathrm{R}$ & 3 & E & $\mathrm{NO}$ & $\mathrm{NO}$ \\
\hline 25 & F.B. & 55 & F & $\mathrm{R}$ & 5 & I Bilat. & NO & NO \\
\hline 26 & G.B. & 49 & $\mathrm{~F}$ & $\mathrm{~L}$ & 3 & $\mathrm{E}$ & NO & $\mathrm{NO}$ \\
\hline 27 & M.C. & 52 & M & $\mathrm{L}$ & 6 & I Bilat. & NO & NO \\
\hline 28 & A.S. & 44 & $\mathrm{~F}$ & $\mathrm{~L}$ & 6 & $\mathrm{E}$ & NO & $\mathrm{NO}$ \\
\hline 29 & C.V. & 56 & F & $\mathrm{L}$ & 5 & I & NO & $\mathrm{NO}$ \\
\hline 30 & C.Q. & 58 & $\mathrm{~F}$ & $\mathrm{R}$ & 5 & $\mathrm{E}$ & $\mathrm{NO}$ & $\mathrm{NO}$ \\
\hline 31 & M.W.L. & 43 & M & $\mathrm{R}$ & 5 & $\mathrm{~L}$ & NO & NO \\
\hline 32 & A.O. & 49 & $\mathrm{~F}$ & $\mathrm{R}$ & 5 & $\mathrm{E}$ & NO & NO \\
\hline
\end{tabular}




\begin{tabular}{|c|c|c|c|c|c|c|c|c|}
\hline 33 & M.D.A. & 60 & F & $\mathrm{R}$ & 5 & I & $\mathrm{NO}$ & $\mathrm{NO}$ \\
\hline 34 & M.P. & 62 & F & $\mathrm{L}$ & 4 & $\mathrm{~L}$ & $\mathrm{NO}$ & $\mathrm{NO}$ \\
\hline 35 & B.C. & 60 & F & $\mathrm{R}$ & 4 & E & NO & $\mathrm{NO}$ \\
\hline 36 & C.E. & 44 & F & $\mathrm{L}$ & 4 & $\mathrm{~L}$ & $\mathrm{NO}$ & $\mathrm{NO}$ \\
\hline 37 & C.F. & 48 & $\mathrm{~F}$ & $\mathrm{R}$ & 4 & E & $\mathrm{NO}$ & $\mathrm{NO}$ \\
\hline 38 & C.N. & 48 & $\mathrm{~F}$ & $\mathrm{R}$ & 4 & $\mathrm{~L}$ & $\mathrm{NO}$ & $\mathrm{NO}$ \\
\hline 39 & M.C. & 51 & M & $\mathrm{L}$ & 3 & I & $\mathrm{NO}$ & $\mathrm{NO}$ \\
\hline 40 & I.D. & 55 & $\mathrm{~F}$ & $\mathrm{R}$ & 5 & L Bilat. & NO & $\mathrm{NO}$ \\
\hline 41 & R.D. & 52 & $\mathrm{~F}$ & $\mathrm{~L}$ & 4 & $\mathrm{~L}$ & NO & $\mathrm{NO}$ \\
\hline 42 & E.F. & 58 & F & $\mathrm{R}$ & 4 & I & $\mathrm{NO}$ & $\mathrm{NO}$ \\
\hline 43 & V.F & 48 & M & $\mathrm{R}$ & 4 & $\mathrm{~L}$ & $\mathrm{NO}$ & $\mathrm{NO}$ \\
\hline 44 & M.G. & 62 & $\mathrm{~F}$ & $\mathrm{~L}$ & 4 & $\mathrm{~L}$ & $\mathrm{NO}$ & $\mathrm{NO}$ \\
\hline 45 & M.M. & 53 & M & $\mathrm{L}$ & 4 & E & NO & $\mathrm{NO}$ \\
\hline 46 & P.F. & 47 & $\mathrm{~F}$ & $\mathrm{R}$ & 4 & $\mathrm{E}$ & $\mathrm{NO}$ & $\mathrm{NO}$ \\
\hline 47 & G.A. & 48 & $\mathrm{~F}$ & $\mathrm{~L}$ & 5 & I & $\mathrm{NO}$ & $\mathrm{NO}$ \\
\hline 48 & G.A.M. & 44 & F & $\mathrm{L}$ & 4 & I & $\mathrm{NO}$ & $\mathrm{NO}$ \\
\hline 49 & S.G. & 59 & $\mathrm{~F}$ & $\mathrm{~L}$ & 5 & E Bilat. & $\mathrm{NO}$ & $\mathrm{NO}$ \\
\hline 50 & F.D. & 62 & $\mathrm{~F}$ & $\mathrm{R}$ & 4 & I & $\mathrm{NO}$ & $\mathrm{NO}$ \\
\hline 51 & V.A. & 46 & $\mathrm{~F}$ & $\mathrm{~L}$ & 4 & $\mathrm{~L}$ & NO & $\mathrm{NO}$ \\
\hline 52 & V.R. & 45 & $\mathrm{~F}$ & $\mathrm{~L}$ & 4 & $\mathrm{~L}$ & NO & NO \\
\hline 53 & V.M. & 47 & M & $\mathrm{R}$ & 5 & I & NO & $\mathrm{NO}$ \\
\hline 54 & S.I. & 47 & $\mathrm{~F}$ & $\mathrm{R}$ & 4 & E & $\mathrm{NO}$ & $\mathrm{NO}$ \\
\hline 55 & D.D. & 47 & $\mathrm{~F}$ & $\mathrm{R}$ & 5 & E Bilat. & NO & $\mathrm{NO}$ \\
\hline 56 & L.T. & 49 & $\mathrm{~F}$ & $\mathrm{R}$ & 6 & I Bilat. & NO & $\mathrm{NO}$ \\
\hline 57 & A.L.N. & 54 & $\mathrm{M}$ & $\mathrm{R}$ & 5 & E & NO & $\mathrm{NO}$ \\
\hline 58 & M.F.P. & 43 & $\mathrm{M}$ & $\mathrm{R}$ & 6 & I & NO & $\mathrm{NO}$ \\
\hline 59 & A.L. & 57 & $\mathrm{M}$ & $\mathrm{R}$ & 4 & I & NO & $\mathrm{NO}$ \\
\hline 60 & G.F. & 55 & $\mathrm{~F}$ & $\mathrm{R}$ & 6 & L Bilat. & $\mathrm{NO}$ & $\mathrm{NO}$ \\
\hline
\end{tabular}

\section{Histological Analysis}

Once arrived to the laboratory of Anatomical Pathology, the material underwent the following protocol: decalcification with osteodec (EDTA, $\mathrm{HCl}$ mixture) for $48 \mathrm{~h}$, subject to fixation in neutral buffered formalin ( $\mathrm{pH} 7)$. Then the material was placed in paraffin inclusion: from paraffin, 5-micron sections were obtained, then stained with hematoxylin-eosin and PAS procedure (periodic acid-Schiff's reagent).

\section{Histomorphometric Analysis}

We also performed a histomorphometric analysis to assess the quantitative and qualitative variables of the new-synthesis material in order to compare the use of the two grafting materials for the replacement of bone loss.

After intraoperative bone sampling, we planned implant insertion, which was case-specific and with delayed loading.

\section{Follow-up}

The treated patients were included in a follow-up treatment involving pharmacological treatment with Amoxicillin+Clavulanate (1g per os every 12 hours for 7 days) together with Ketoprofen (100mg im every 12 hours for 5 days) and Chlorhexidine mouthwash
$(0,12 \%$, every 12 ore for 14 days); the suture removal was scheduled after 7 days. X-ray OPT and Denta-Scan was performed six months after surgery.

\section{Results}

This treatment involved 60 patients presenting with major atrophies of the upper maxilla requiring preimplant reconstructive surgery by sinus lift.

72 sinus lifts were performed with subsequent implant insertions (240 was the number of placed implants). During sinus lift, no perforation of the sinus membrane was recorded. In all treated cases, the preimplant reconstructive surgery and the subsequent rehabilitation by implant were successful.

\section{Histological Results}

\section{I) "Early" protocol}

In this protocol, we had the most interesting results on the effectiveness of PRF used as a grafting material.

The histological results proved that the samples collected from the "test-side" after 106 days with the adding of PRF "were constituted by lamellar bone tissue with acellular osteocyte lacunae and an intensely-eosinophilic bone matrix mixed with fragments of lamellar bone tissue with inhabited osteocyte 
lacunae and a slightly-eosinophilic bone matrix (probably to be ascribed to the newly-formed bone tissue). In such fragments, osteocytes are sometimes disposed horizontally and border the bone trabeculae. The interposed stroma is relaxed and richly vascularized" (Figure 1/a - b - c).

Instead, the samples collected from the "Control-Side" revealed that "the fragments were constituted by trabeculae of lamellar bone tissue with inhabited osteocyte lacunae, immersed in a dense poorly-cellular fibrous stroma, in which are included fragments of lamellar bone with empty osteocyte lacunae and with an intensely-eosinophilic bone matrix. We also find roughly globular lacunae, optically empty, probably as a result of the granules of Bio-Oss not yet integrated into the bone matrix". (Fig. 1/d)
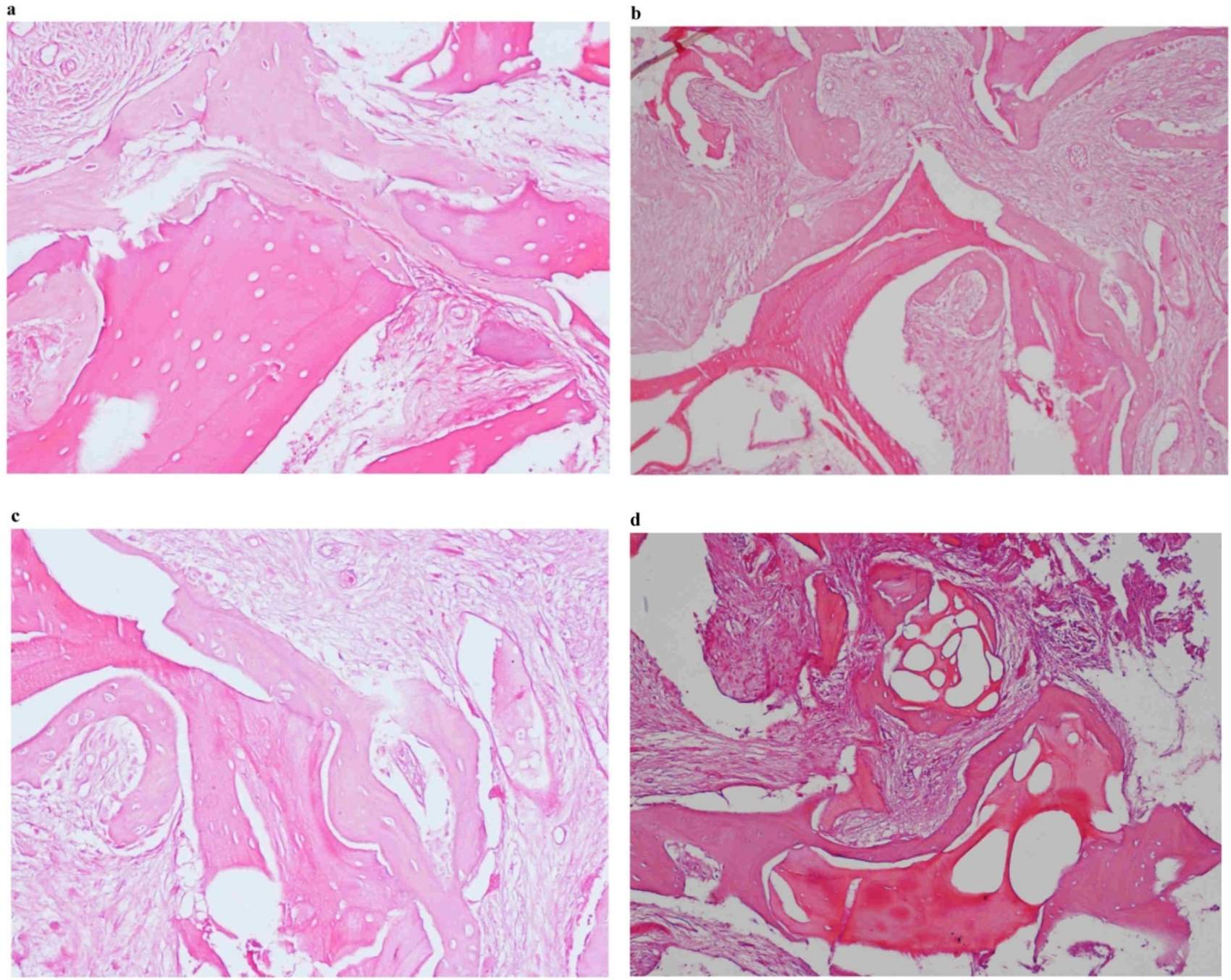

Fig. I. a-b-c: Histological pictures referring to Test-Side of "EARLY Protocol”. d: Histological picture referring to Control-Side of "EARLY Protocol". 


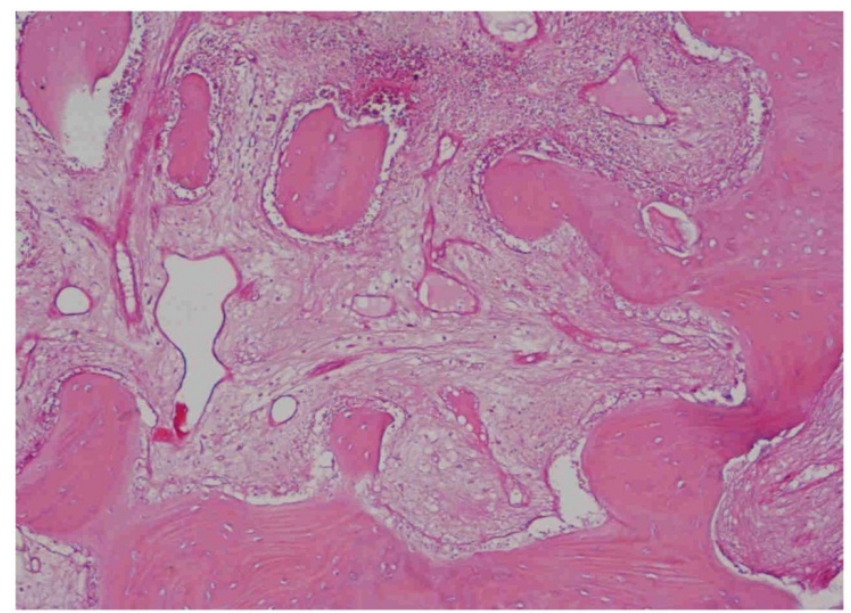

Fig. 2. Histological picture referring to "INTERMEDIATE Protocol".

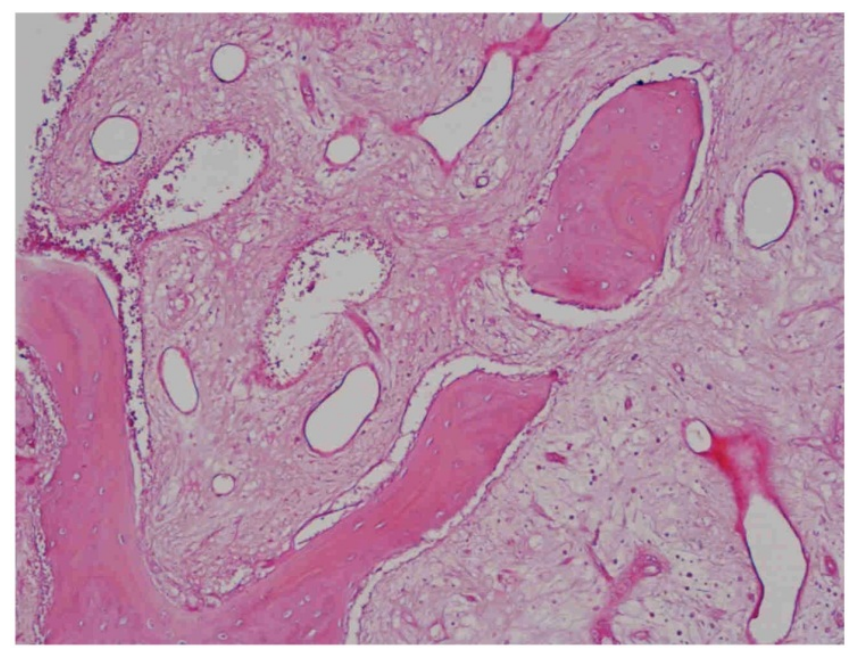

Fig. 3. Histological picture referring to "LATE Protocol".

\section{Histomorphometric Results}

Histomorphometric analysis of the samples of "test-side" group was performed, and then compared with the results of samples collected from "control-side" group.

The preliminary analysis of the histological material shows, in the three protocols (early - intermediate - late), the presence of mineralized trabecular bone.

The presence of both osteocytes and osteoblasts, although in small quantity, indicates the presence of osteoinductive activity, probably caused by the increased quantity of PRF, compared to the samples collected from "control-side".
However, the histomorphometric investigation and the histological analysis revealed that the good osteoconductive capacity of PRF leads to the production of new bone, already 106 days after reconstructive surgery.

The histological analysis also revealed that the use of PRF produced, already in the "early" protocol, a remarkable neoangiogenesis acting as a good trophic support to the newly-formed bone tissue. This reduced the areas of non-vital bone compared to the "control-side" (Table 2).

\section{Clinical and Radiological Results}

From a clinical standpoint, we noticed perimplant tissue healing without complications: in all treated cases, the surgical protocol and the implant-prosthetic rehabilitation were successful, as confirmed by the fulfillment of Albrektsson's implant success criteria. ${ }^{1}$

It was impossible to verify the last Albrektsson's implant success criterion ${ }^{1}$ (maintaining of implants on $85 \%$ at 5 years, on $80 \%$ at 10 years), because the patients had been followed for less than 3 years. Primary implant stability was assessed by means of RFA (Resonance Frequency Analysis) (Osstell ${ }^{\circledR}$ ). Data of measurements was recorded as ISQ values (Implant Stability Quotient): for each implant were performed three measurements, and from these values, a mean value was calculated and recorded. Mean ISQ value was 37.2 (sd: 4.2) in "early protocol group" implants, 36.8 (sd:6.1) in "intermediate protocol group" implants and was 39.1 (sd: 9.0) in "late protocol group" implants.

No statistically significant differences $(p>0.05)$ regarding ISQ mean values were found between test groups and control groups in each of protocol we performed. After $36 \pm 10$ months of functional loading, no implant was lost (cumulative survival rate: 100\%).

The real increase in perimplant bone density was evaluated by the analysis of Orthopantomographies and Dentascan x-rays, as well as by a personal computer and by the "Implant3D" software, which allowed for a three-dimensional reconstruction of the treated area. The tomographic sections were scanned and analyzed by computer software, so that the tomograms corresponding to the pre- e post-operative conditions could be compared.

The radiological control after six months allowed verifying the presence of newly-formed bone tissue, well-integrated with the residual bone, and of a close contact between implants and the newly-formed bone in the apical area. 
Table 2. Histomorphometric Evaluations. We evaluate the results of "Test-Side" and "Control-Side" in the three protocols.

\begin{tabular}{lll}
\hline “EARLY” PROTOCOL & Test Side & Control Side \\
\hline Medullary Spaces (\%) & 70,2 & 68,44 \\
Osteoid borders (\%) & 7,01 & 5,12 \\
Trabecular bone (\%) & 22,79 & 26,44 \\
“INTERMEDIATE” PROTOCOL & Test Side & Control Side \\
Medullary Spaces (\%) & 70,01 & 68,18 \\
Osteoid borders (\%) & 3,84 & 3,12 \\
Trabecular bone(\%) & 26,15 & 28,7 \\
PROTOCOLLO “LATE” & Test Side & Control Side \\
Medullary Spaces (\%) & 61,41 & 58,15 \\
Osteoid borders (\%) & 3,53 & 2,88 \\
Trabecular bone(\%) & 37,06 & 38,97 \\
\hline
\end{tabular}

\section{Discussion}

The purpose of treating toothless areas with endosseous implants has often clashed with the assumption that the loss of teeth is reflected in a progressive bone resorption ${ }^{25}$.

The modern and sophisticated techniques of GBR involve the use of grafting materials in order to restore anatomy and physiology of the areas with bone decrement 26 .

The autologous bone is the selected grafting material (gold standard) as it is the only material to have osteogenic properties apart from osteoinductive and osteoconductive properties 9-11. However, the grafts performed with deproteinized bovine bone (Bio-Oss) are largely used in sinus lift 27-28; in fact, deproteinized bovine bone is able to cause a physiological process of perimplant bone reshaping, with neoapposition and significant bone gain thanks to its chemical and physical characteristics, which are very similar to those of the human bone. Beyond the advantage of good osteoconductive properties, the mineral of bovine origin does not involve risks of intolerance or infection; the biocompatibility of the material depends on its preparation, aiming at eliminating the protein and lipidic components from the original material and making it inorganic before being sterilized by heat and irradiation 12,13.

Platelet Rich Fibrin (P.R.F.) was first described by Dr. Choukroun and introduced with the European Directive n. 2004/23/CE of March 31, 2004.

Choukroun et al. reported encouraging results by using fibrin rich in growth factors for bone regeneration in sinus-lift ${ }^{19}$. Histological studies showed an equal bone growth and trabecular organization between the areas treated with PRF and those of the control sample (F.D.B.A.); the rate of vital bone/inert bone of the neoformed trabecular bone revealed that, in these studies, about $1 / 3$ of neoformed bone graft is inert while over $2 / 3$ of new bone is vital. The Authors concluded that, with the aid of PRF, the healing time is significantly reduced and the implant can be placed already 4 months (120 days) after surgery. A histological control 4 months later revealed that bone quality between the areas treated with PRF and FDBA and the control areas were the same ${ }^{8}$.

\section{Conclusions}

The clinical cases reported in the present study achieved a clinical success rate of $100 \%$ in sinus lift, by using the PRF obtained following Choukroun's protocol ${ }^{16}$. Besides, the use of PRF and piezosurgery reduced the healing time, compared to the 120-150 days described in literature ${ }^{6-8}$, favoring optimal bone regeneration. At 106 days, it is already possible to achieve good primary stability of endosseous implants, though lacking of functional loading.

Platelet-rich fibrin is a grafting material that eliminates any risk of xenopathy transmission; besides, its gelatinous consistency favors clot stability and the membranous shape allows creating a natural "barrier effect" on the bone breaches that were opened in the surgical areas.

In the light of the good regenerative and implant technique suggested in the present study, as well as other similar studies ${ }^{29}$, in order to achieve therapeutic success, it will be fundamental to combine a strong initial motivation of patients and increase their level of collaboration during the various reconstruction stages.

\section{Acknowledgments}

The study was carried out in collaboration with the Dental Clinic "Calabrodental" and the Institute of 
Research "Tecnologica". This research work has been the degree thesis of Dr. Marco Tatullo.

\section{Competing Interests}

The authors have declared that no competing interest exists.

\section{References}

1. Albrektsson T, Zarb GA, Worthington $P$, et al. The long-term efficacy of currently used dental implants: a review and proposed criteria of success. Int J Oral Maxillofac Impl. 1986; 1:1-25.

2. Tallgren A. The continuing reduction of the residual alveolar ridge in complete denture wearers. A mixed longitudinal study covering 25 years. J Prosthet Dent 1972;27:120-132.

3. Jovanovic SA, Schenk RK, Orsini M. Supracrestal bone formation around dental implants: an experimental dog study. Int J Oral Maxillofac Implants 1995;10:23-31.

4. Misch CE, Dietsch F. Bone grafting materials in implant dentistry. Implant Dent 1993; 2: 158-167.

5. Nystrom E, Legrel PE, Forssel A, et al. Combined use of bone graft and implants in the severly resorbed maxilla. Postoperative evaluation by computed tomography. Int J Oral Maxillofac Surg 1993; 24: 20-25.

6. Adell R, Lekholm U, Grondahl K, Branemark PI, Linstrom J, Jacobsson $\mathrm{M}$. Reconstruction of severly resorbed edentulous maxillae using osseointegrated fixtures in immediate autogenous bone grafts. Int J Oral Maxillofac Implants 1990; 5: 233-246.

7. van der Wal KGH, de Visscher J, Stoelinga JW. The autogenous inner table iliac bone graft. Int J Oral Maxillofac Surg 1986; 14: 22-25.

8. Chiapasco M, Romeo E. Chirurgia preimplantare nelle atrofie dei mascellari. In: "La Riabilitazione Implantoprotesica nei casi complessi". UTET. 2003: 142-159.

9. Preti G. Implantologia: Nuove acquisizioni e aspetti clinici. In: "Riabilitazione Protesica". UTET. 2003: 203-206.

10. Friberg B, Sennerby L, Roos J, Lekholm U. Identification of bone quality in conjunction with insertion of titanium implants. Clin Oral Implants Res 1995; 6: 213-219.

11. Lekholm U, Wannfors K, Isaksson S, Adielsson B. Oral implants in combination with bone grafts. Int J Oral Maxillofac Surg 1999; 28: 181-187.

12. Yildirim M, Spiekermann H, Biesterfeld S, Edelhoff D. Maxillary sinus augmentation using xenogenic bone substitute material Bio-Oss in combination with venous blood. A histologic and histomorphometric study in humans. Clin Oral Implants Res. 2000 Jun;11(3):217-29.

13. Inchingolo F, Bux M, Ronzulli F, Di Franco $\mathrm{M}$. Il rialzo del seno mascellare e riabilitazione protesica. Quintessence International 1996; : 639-642.

14. Lakey LA, Akella R, Ranieri JP. Angiogenesis: implications for tissue repair. In: Davies JE, ed. Bone engineering. Toronto: Em Squared Incorporated; 2000: 137-42

15. Schmid J, Wollkamm B, Hammerle CH, Gogolewski S, Lang NP. The significance of angiogenesis in guided bone rigeneration. A case report of a rabbit experiment. Clin Oral Implants Res 1997 Jun;8(3):244-8.

16. Dohan DM, Choukroun J, Diss A, Dhoan SL, Dhoan AJ, Mouhyi J, Gogly B. Platelet-rich fibrin (PRF): a second-generetion platelet concentrate. Part I: technological concepts and evolution. Oral Surg Oral Med Oral Pathol Oral Radiol Endod. 2006 Mar;101(3):e37-44.

17. Dhoan DM, Choukroun J, Diss A, Dhoan SL, Dhoan AJ, Mouhyi J, Gogly B. Platelet-rich fibrin (PRF): a second-generetion platelet concentrate. Part II: platelet-related biologic features. Oral Surg Oral Med Oral Pathol Oral Radiol Endod. 2006 Mar;101(3):e45-50.

18. Dhoan DM, Choukroun J, Diss A, Dhoan SL, Dhoan AJ, Mouhyi J, Gogly B. Platelet-rich fibrin (PRF): a second-generetion platelet concentrate. Part III: leucocyte activation: a new feature for platelet concentrate?. Oral Surg Oral Med Oral Pathol Oral Radiol Endod. 2006 Mar;101(3):e51-5.

19. Choukroun J, Diss A, Simonpieri A, Girard MO, Schoeffler C, Dhoan SL, Dhoan AJ, Mouhyi J, Dohan DM. Platelet-rich fibrin (PRF): a second-generation platelet concentrate. Part V: histologic evaluation of PRF effect on bone allograft maturation in sinus lift. Oral Surg Oral Med Oral Pathol Oral Radiol Endod. 2006 Mar; 101(3):299-303.

20. Diss A, Dohan DM, Mouhyi J, Mahler P. Osteotome sinus floor elevation using Choukroun's platelet-rich fibrin as grafting material: a 1-year prospective pilot study with microthreaded implants. Oral Surg Oral Med Oral Pathol Oral Radiol Endod. 2008 May;105(5):572-9.
21. Carlson NE, Roach R Jr. Platelet rich plasma - Clinical applications in dentistry. J Am Dent Assoc, 2002; 133: 1383.

22. Whitman DH, Berry RL, Green DM. Platelet gel - An autologous alternative to fibrin glue with applications in oral and maxillofacial surgery. $J$ Oral Maxillofac Surg, 1997; 55: 1294.

23. Banks R.E., Forbes M.A., Kinsey S.E., et al. Release of the angiogenic cytokine VEGF from platelets - Significance for VEGF measurements and cancer biology. Br J Cancer, 1998; 77: 956.

24. Thomas K.A. Vascular endothelial growth factor, a potent and selective angiogenic agent. J Biol Chem, 1996; 271: 603.

25. Marx R.E. Clinical application of bone biology to mandibular and maxillary reconstruction. Clin Plast Surg 1994;21:377-92

26. Inchingolo $F$, Tatullo $M$, Marrelli $M$, Inchingolo $A D$, Corelli $R$, Inchingolo AM, Dipalma G, Abenavoli FM. Clinical case-study describing the use of skin-perichondrium-cartilage graft from the auricular concha to cover large defects of the nose. Head Face Med. 2012 Mar 19;8(1):10.

27. Pacifici L, Casella F, Ripari M. Lifting of the maxillary sinus: complementary use of platelet rich plasma, autologous bone deproteinised bovine bone. Case report. Minerva Stomatol. 2003 Sep;52(9):471-8.

28. Pacifici L, Casella F, Maggiore C. Platelet rich plasma (PRP): potentialities and techniques of extraction. Minerva Stomatol. 2002;51(7-8):341-50.

29. Inchingolo F, Tatullo M, Marrelli M, Inchingolo AM, Scacco S, Inchingolo AD, Dipalma G, Vermesan D, Abbinante A, Cagiano R. Trial with Platelet-Rich Fibrin and Bio-Oss used as grafting materials in the treatment of the severe maxillar bone atrophy: clinical and radiological evaluations. Eur Rev Med Pharmacol Sci. 2010 Dec;14(12):1075-84. 